\title{
A Patient With Repetitive Variant Angina Attacks That Could be Controlled With Amiodarone
}

\author{
Yücel Yılmaz ${ }^{1}$, Fatma Esin ${ }^{2}$, Onur Kadir Uysal ${ }^{1}$, Mustafa Duran ${ }^{3}$, Hüseyin Arınç ${ }^{1}$, Mehmet \\ Tuğrul İnanç ${ }^{4}$
}

${ }^{1}$ Kayseri Education and

Research Hospital,

Department of Cardiology,

Kayseri, Turkey;

${ }^{2}$ Denizli State Hospital,

Department of Cardiology,

Denizli, Turkey;

${ }^{3}$ Ankara Education and

Research Hospital,

Department of Cardiology, Ankara, Turkey;

${ }^{4}$ Erciyes University, School of Medicine, Department of Cardiology, Kayseri,

Turkey

\section{Corresponding Author:}

Dr. Yücel Yılmaz

\section{Address:}

Kayseri Education and Research Hospital, Department of Cardiology, Kayseri, Turkey;

\section{E-mail:}

dryyilmaz@hotmail.com

Başvuru Tarihi/Received : 15-05-2014

Kabul Tarihi/Accepted:

30-06-2014

\section{ABSTRACT}

Prinzmetal variant angina due to epicardial coronary artery spasm is a disease usually treated with drug therapy with successful results. However, a small percentage of patients are resistant to medical therapy. In this report, we present a patient with recurrent vasospastic episodes who was refractory to conventional pharmacological treatment and successfully treated with an amiodarone treatment. We also discuss the therapeutic effectiveness of amiodarone therapy for vasospastic angina.

Key words: Prinzmetal Angina, Amiodarone 


\section{INTRODUCTION}

Variant angina is characterized by recurrent attacks of angina at rest and associated with ST-segment elevation or depression. It is caused by an occlusive or subocclusive epicardial coronary artery spasm. Five to thirty percent of the patients with variant angina continue to have symptoms despite of aggressive medical treatment (1-3). We present a case that angina attacks could not be prevented with full antianginal therapy while addition of amiodarone to these medications subsided the attacks entirely.

\section{CASE REPORT}

A 46-year-old woman suffered from sudden onset of severe precordial stabbing pain. The patient's risk factors for ischemic heart disease were smoking (1 packet/ 30 years) and hypertension. Physical examination findings were normal. The electrocardiogram (ECG) showed normal sinus rhythm with a heart rate 67/ bpm, and negative T-waves in leads DI, aVL, V1-V2. The complete blood count and biochemistry profiles were normal. The patient was diagnosed with acute coronary syndrome and heparin, aspirin, IV nitroglycerin and betablocker therapies were initiated. Troponin and echocardiographic parameters were normal. In diagnostic catheterization, mild stenosis of the proximal left anterior descending artery (LAD) was established and other coronary arteries were normal (Figure 1).

On the follow up she complained about chest pain. ST segment elevations at D1, aVL, V1-4 and reciprocal depression at DII-DIII-aVF were detected on ECG (Figure 2a). Then her rhythm degenerated to ventricular fibrillation and electrical defibrillation was performed. Oral metoprolol therapies were increased and amiodarone infusion was started.

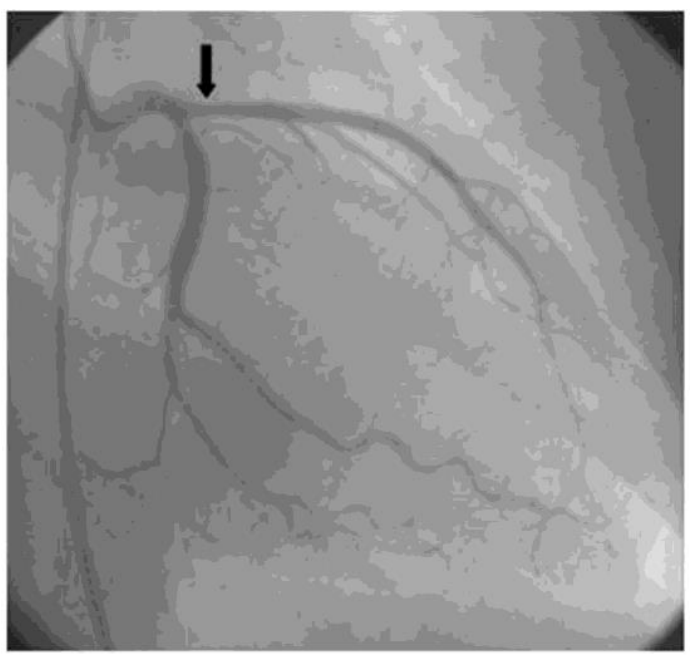

Figure 1: Coronary angiogram. Stenosis of the proximal left anterior descending artery (Black arrow)

Then the pain was resolved and ECG became to baseline (Figure 2b). Amiodarone infusion discontinued after 24 hours (total 1500 $\mathrm{mg}$ ). After discontinuation of intravenous amiodarone, she suffered from repeated chest pain and revealed ECG changes with ST elevations every day. Repetitive chest pains and ECG changes were resolved with additional intravenous calcium antagonists and nitrate therapy. She was diagnosed to have variant angina pectoris the beta-blocker therapy was changed to verapamil therapy (oral $240 \mathrm{mg} / \mathrm{d}$ ). Trimetazidine $(60 \mathrm{mg} / \mathrm{d})$ and amlodipine (10 $\mathrm{mg} / \mathrm{d}$ ) were added. In spite of these therapies anginal attacks continued every day. Amiadorone therapy was started again at the seventh day for ventricular fibrillation risk and probable anti-ischemic effect (oral $800 \mathrm{mg} / \mathrm{d}$ ). After two days with oral amiodarone treatment the patient was free of chest pain. 

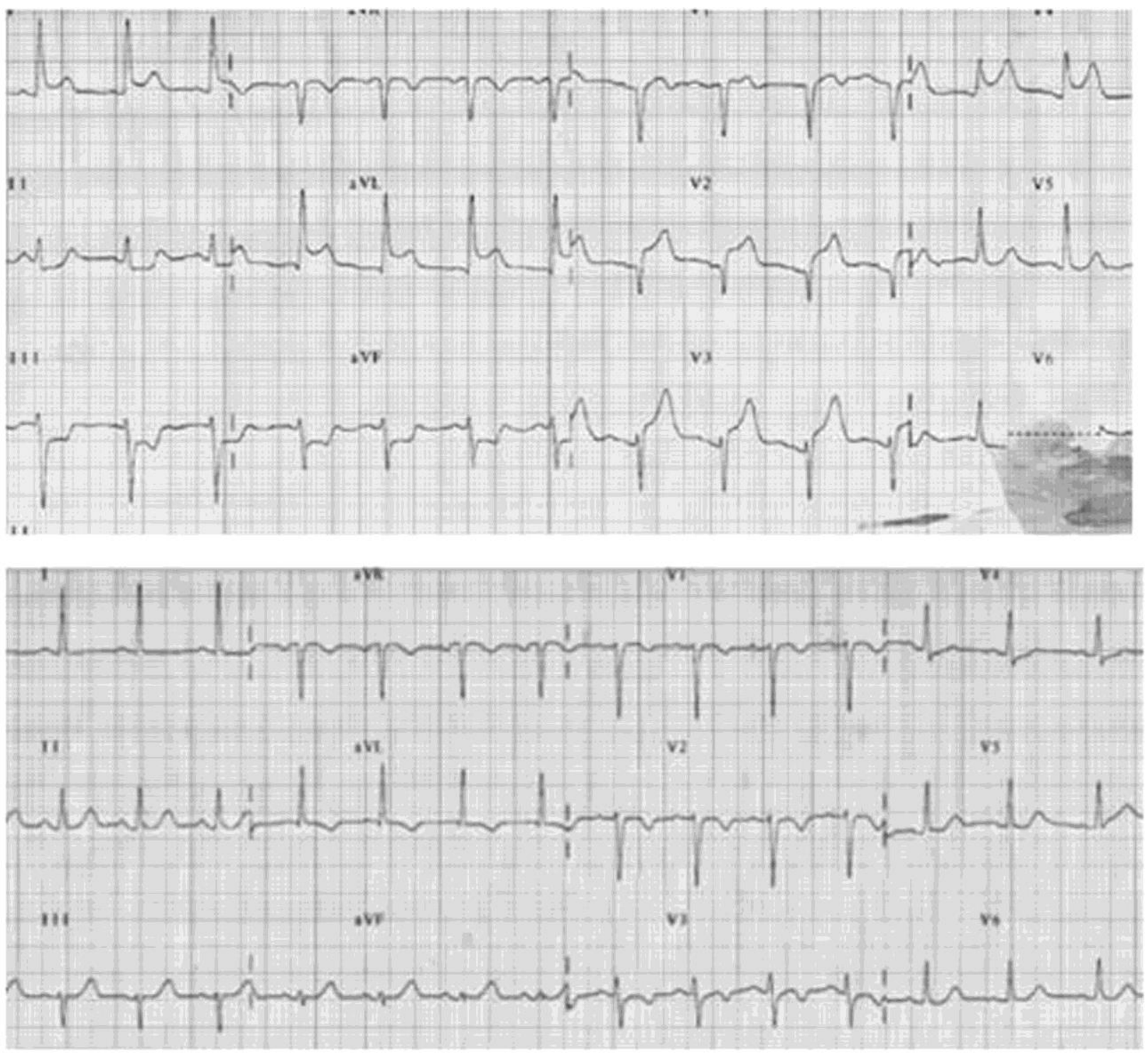

Figure 2: ST-segment changes: (a) ECG during angina attack; (b) ECG after pain episode.

\section{DISCUSSION}

Variant angina pectoris is associated with ST elevation; the myocardial area of ST elevation corresponds to the distribution of a major coronary artery spasm (4). The exact prevalence of variant angina is unknown; however, it is considered to be less common than either typical, exertional angina or unstable angina (5).

The mechanism leading to spontaneous spasm is vagal activity decrease. Endothelial dysfunction through abnormalities of nitric oxide realese and hypercontractility of vascular smooth muscle in spastic area are major factors in the development of coronary artery spasm in variant angina (6). In about two thirds of the patients coronary artery spasm occurs at the level of an atherosclerotic lesion (7). We did not perform any provocation test to stimulate coronary vasospasm during the coronary angiography. Arrhythmias are extremely rare and the conventional medical treatment offers relief of symptoms and a relatively good prognosis (8). Nitrates and calcium channel blockers are classically used medicine.

However, amiodarone has widely been used as an antiarrhythmic agent for years, it was a synthesized as a coronary dilator for use as an antianginal agent over 20 years ago (9). It was 


\section{DOI: $10.16899 /$ ctd.67740}

used in the treatment of variant angina in 1980s. Because of the high effectiveness of other antiischemic agents and its relatively high rate of adverse effects, it was no longer used for its anti-ischemic effects. Therefore, studies that about anti-ischemic and anti-spastic effects of amiodarone is very limited. In this case, the antianginal agents were not effective. However, the combination of amiodarone therapy stopped the episodes of chest pain. Amiodarone shows important hemodynamic and anti-ischemic properties in human when given intravenously (10). It is an immediate reduction in vascular resistance, decrease in left ventricular systolic and aortic pressures (10). The antianginal effect of amiodarone may be due to its negative choronotropic effect, the decrease in systemic blood pressure, reduction myocardial oxygen consumption, reduction in coronary vascular resistance or inhibition of alfa and beta receptors (11). Rutitzky et al. reported that oral amiodarone therapy suppressed chest pain in patients with vasospastic angina pectoris and during amiodarone treatment, ergonovine vasoconstriction was inhibited. And it is spasmolytic drug which effects coronary smooth muscle relaxation. In addition to, the vasodilator effect of amiodarone is performed by direct action and alpha receptor antagonism of coronary vasculature (11). Meyer et al. discovered that oral amiodarone therapy is an effective antianginal agent in patients with angina pectoris on conventional therapy (12).

In this patient, the anginal episodes could not be controlled, despite the maximal medical treatment which the patient could tolerate. After the amiodarone therapy, the anginal episodes were resolved. She suffered from recurrent chest pain after discontinuation of IV amiodarone therapy, although oral amiodarone therapy was benefit on episodes of chest pain. Data of effects of orally administered amiodarone were limited; anti-ischemic effect of amiodarone might be depending of the loading regimen similar to the antiarrhythmic effect.

In conclusion, the amiodarone therapy may be used in variant angina, in which other traditional therapies are not beneficial.

\section{REFERENCES}

1. Freedman SB, Richmond DR, Alwyn M, Kelly DT. Late follow-up (41 to 102 months) of medically treated patients with coronary artery spasm and minor atheroslerotic coronary obstructions. Am J Cardiol 1986;57:1261-3

2. Egashira K, Kikuchi Y, Sagara T, Suguhara M, Nakamura M. Long term prognosis of vasospastic angina without significant atherosclerotic coronary artery disease. Jpn Heart J 1987;28:841- 9.

3. Bory M, Pierron F, Panagides D, Bonnet JL, Yvorra S, Desfossez. Coronary artery spasm in patients with normal or near normal coronary arteries. Eur Heart $\mathbf{J}$ 1996;17:1015-21

4. Kawano H, Ogawa H. Endothelial Function and Coronary Spastic Angina. Internal Medicine 2005;44: 91-9.

5. David J. D'Agate, DO, Richard Schwartz, DO, Jason M. Lazar, MD. Coronary Vasospasm-Induced Ventricular Tachyarrhythmias. The Journal of Invasive Cardiology 2002;10:609-14.

6. Stern S, Bayes de Luna A. Coronary Artery Spasm: A 2009 Update. Circulation 2009;119;2531-2534

7. Kaski JC, Crea F, Meran D, Rodriguez L, Araujo L, Chierchia S, Davies G, Maseri A. Local coronary supersensitivity to diverse vasoconstrictive stimuli in patients with variant angina. Circulation 1986;74:1255-65

8. Nakamura M, Takeshita A, Nose Y. Clinical characteristics associated with myocardial infarction, arrhythmias, and sudden death in patients with vasospastic angina. Circulation 1987;75:1110-6.

9. Singh BN. Amiodarone: historical development and pharmacologic profile. Am Heart J. 1983 Oct;106(4 Pt 2):788-97.

10. Remme WJ, Hoogenhuyze DV, Krauss XM, Hofman A, Kruyssen DACM, Storm CJ. Acute Hemodynamic and Antiischemic Effects of Intravenous Amiodarone. Am J Cardiol. 1985;55:639-44.

11. Rutitzky B, Girotti AL, Rosenbaum MB. Efficacy of chronic amiodarone therapy in patients with variant angina pectoris and inhibition of ergonovine coronary constriction. Am Heart J. 1982;103:38-43.

12. Meyer BJ, Gschwend S, Marx B, Amann FW. Antianginal effect of amiodarone in therapy-resistant angina pectoris. Schweiz Med Wochenschr. 1992 Jan 18;122(3):70-2 